\title{
International Metallographic Contest and Exhibit
}

\author{
Co-Sponsored by the International Metallographic Society and ASM International. \\ Deadline for entries is July 20, 2013.
}

(C) Springer Science+Business Media New York and ASM International 2013

The International Metallographic Contest is an annual event co-sponsored since 1972 by the International Metallographic Society and ASM International. Its goal is to advance the science of microstructural analysis by providing an opportunity for those interested in material properties and characterization to display their work and communicate significant scientific information. There are 11 different classes of competition covering all fields of light and electron microscopy. In Classes 1 through 8 multiple images and captions are expected to be used to describe how microstructural analysis was used to help solve a problem or to describe a unique or unusual technique. Classes 9, 10, and 11 are for artistic pictures. It is a truly international competition showcasing the finest work of metallographers, scientists, technicians, and students

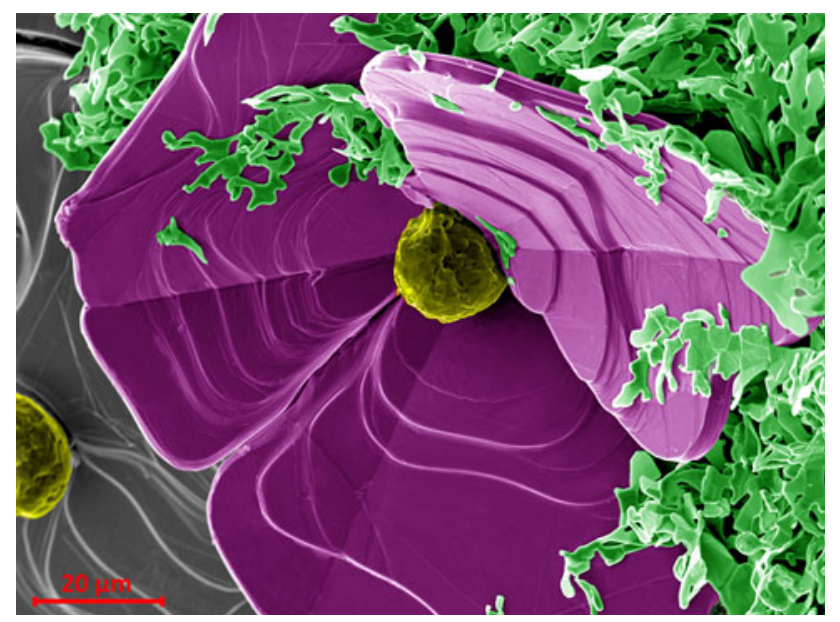

2012-First Place Class 10-Color Only-sponsored by ESI, Engineering and Scientific Investigation: Carbonic Orchid Formed by Graphite Crystals, Shaahin Amini and Reza Abbaschian, University of California Riverside from around the world. The contest is open to all (except contest judges), including non-members.

The Best-in-Show receives the most prestigious award available in the field of metallography, the Jacquet-Lucas Award, which includes a cash prize of $\$ 3,000$. The award is named in honor of Dr. Francis F. Lucas, a research microscopist at Bell Labs, who pioneered the use of high magnification and ultraviolet microscopy, and Dr. Pierre Jacquet, who developed the technique of electrolytic polishing, which led to thin-foil electron microscopy.

First, second, and third place winners in Classes 1 through 11 receive $\$ 200, \$ 100$, and $\$ 50$, respectively. The first place winner in Class 6 also receives the DuBoseCrouse Award for Unique, Unusual, and New Techniques

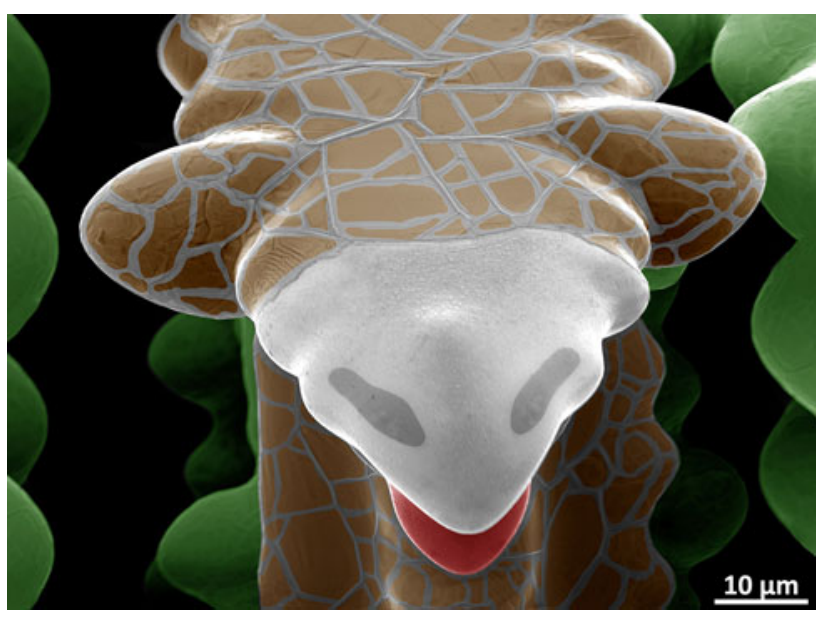

2012-First Place Class 11 Digital Microscopy Artistic: Metallic Giraffe Found Grazing on Microscopic Land of Ni-Al-C, Shaahin Amini, University of California Riverside 


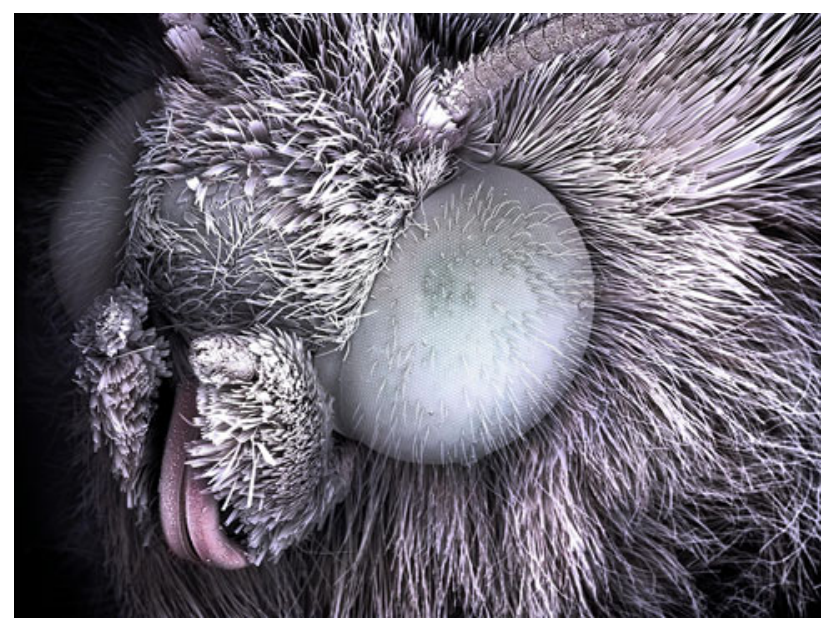

2012-Second Place Class 11 Digital Microscopy Artistic: Owlet Moth, Sheri Neva, SEAL Laboratories

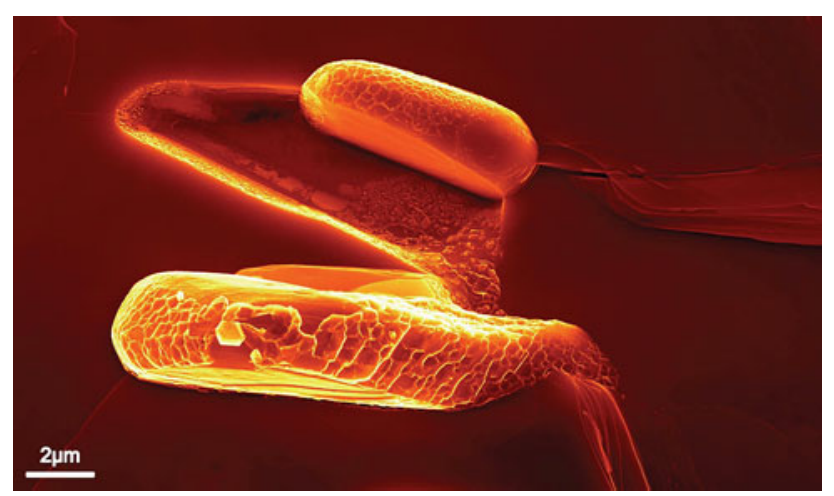

2012-Third Place Class 11 Digital Microscopy Artistic: Mg Lava, Babak Anasori and Michel W. Barsoum, Drexel University

in Microscopy. First place undergraduate student winners in Classes 7 and 8 also receive the George L. Kehl Award plaque. All entries are displayed immediately after judging

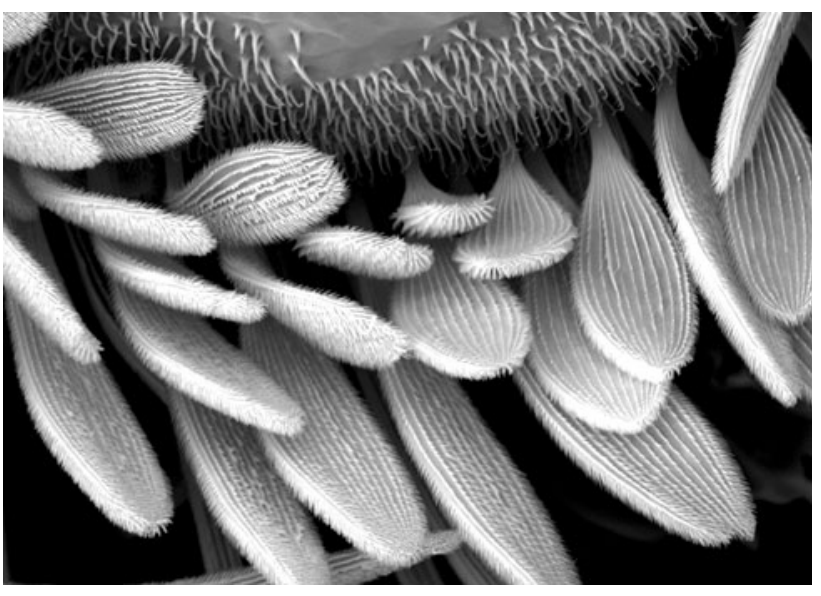

2012-Third Place Class 9 Artistic Microscopy_Black and White Only: Moth Plume Scales, Sheri Neva, SEAL Laboratories

at the IMS Technical meeting and again in the fall during the annual ASM meeting. Selected winning entries are also displayed at the ASM/IMS headquarters at Materials Park and are available for short term exhibition at universities, libraries, ASM Chapter meetings, and other events.

Those interested in competing in the 2013 contest should send entries to

Brian Rose

Columbus Technical Center

950 W. 450 S., Building \#1

Columbus, IN 47201

For additional information including complete rules, tips for creating a winning entry, judging guidelines, and examples of winning entries, visit

www.internationalmetallographicsociety.org/contest.html or e-mail Contest Chair Alice Kilgo at ackilgo@sandia.gov. 